IZA DP No. 6482

Evaluating the Impact of a Reduction in the Generosity of Disability Benefits: The 2008 Spanish Reform

Jose I. Silva

Judit Vall-Castello

April 2012 


\title{
Evaluating the Impact of a Reduction in the Generosity of Disability Benefits: The 2008 Spanish Reform
}

\author{
Jose I. Silva \\ Universitat de Girona \\ Judit Vall-Castello \\ Universitat de Girona, \\ CRES (UPF) and IZA
}

Discussion Paper No. 6482
April 2012

IZA

P.O. Box 7240

53072 Bonn

Germany

Phone: +49-228-3894-0

Fax: +49-228-3894-180

E-mail: iza@iza.org

Any opinions expressed here are those of the author(s) and not those of IZA. Research published in this series may include views on policy, but the institute itself takes no institutional policy positions.

The Institute for the Study of Labor (IZA) in Bonn is a local and virtual international research center and a place of communication between science, politics and business. IZA is an independent nonprofit organization supported by Deutsche Post Foundation. The center is associated with the University of Bonn and offers a stimulating research environment through its international network, workshops and conferences, data service, project support, research visits and doctoral program. IZA engages in (i) original and internationally competitive research in all fields of labor economics, (ii) development of policy concepts, and (iii) dissemination of research results and concepts to the interested public.

IZA Discussion Papers often represent preliminary work and are circulated to encourage discussion. Citation of such a paper should account for its provisional character. A revised version may be available directly from the author. 


\section{ABSTRACT \\ Evaluating the Impact of a Reduction in the Generosity of Disability Benefits: The 2008 Spanish Reform ${ }^{*}$}

We evaluate the effects of a reduction in the generosity of disability benefits in Spain that occurred in 2008. The main objective of the reform was to reduce the amount of benefits for individuals that do not have a long contributory history as the reform introduced a disincentive to apply to the system if the individual does not have 35 years of effective contributions. Theoretical insights are gained with a life-cycle model with heterogeneous disabled workers. The model's simulations predict a reduction in the incentives to apply for disability benefits for partially disabled individuals who do not reach the 35 years of contributions. Diff-in-diff estimates are consistent with our model predictions.

JEL Classification: $\quad$ C33, I18, H51

Keywords: disability benefits reform, life-cycle model, policy evaluation

Corresponding author:

Jose I. Silva

Universitat de Girona

Facultat de Ciències Econòmiques i Empresarials

Campus de Montilivi

1071, Girona

Spain

E-mail: jose.silva@udg.edu 


\section{INTRODUCTION}

During the last years, disability policies have attracted particular attention in OECD countries both because they represent an important source of government expenditure and because societies are becoming more and more concerned about the need to strengthen the integration of disabled individuals in the society.

Countries in the OECD have tightened the conditions to access the unemployment and social assistance schemes introducing several work requirements while, at the same time, early retirement schemes have been limited (or even abolished) because of their well-documented work disincentives. These events have resulted in increasing numbers of pre-retirement individuals entering the disability schemes which, together with the ageing process of developed societies, raises concerns about the mid-term effects of disability expenses on the government's budget.

Furthermore, from 2008 some OECD economies are experiencing a very strong economic crisis that puts additional pressure for the government to cut expenditures and reduce both the public deficit and debt. Spain has been one of the European countries most affected by the crisis and a number of measures have been adopted since 2008 in order to reduce public expenditures, promote employment and reduce unemployment (which has already reached a rate of 22,85 in the third trimester of 2011).

In this context of budget cuts, the Spanish government introduced a reform in the contributory disability system in order to make it more similar to the old-age system and to take into account the number of years that the individual has contributed to the system when calculating the level of disability benefits that he/she will receive.

More precisely, the reform in 2008 stressed that the regulatory base (which is an average of past wages) is multiplied by a percentage that depends on the effective number of years contributed to the Social Security system. If the number of effective years contributed is 35 or more the percentage is $100 \%$. That is, the individual is unaffected by the policy change and he/she will receive the same amount of benefits than before the reform. Before the reform, the regulatory base was not multiplied by this percentage and so the number of years contributed to the system was unrelated to the level of disability benefits that the individual would receive once in the disability rolls. 
In practice this is a way to reduce the amount of benefits for individuals that do not have a long contributory history as well as a disincentive to apply to the system if the individual does not have the 35 years of effective contributions.

Therefore, the objective of this paper is to identify and quantify the effect of the 2008 reform on individual's incentives and disincentives to apply to the disability system. Theoretical insights are gained with a life-cycle model with heterogeneous workers who have to decide to apply or not to the disability system. According to the model, the reform has reduced the incentives to apply for disability benefits for partially disabled individuals who do not reach the 35 years of contributions. Next, we estimate a diff-diff model using a large administrative dataset that allows us to distinguish between the control group (not affected by the reform because they have already contributed 35 years) and the treatment group (affected by the reform because they have contributed less than 35 years) while controlling for a number of personal, regional and businesscycle variables. The estimates results are consistent with our model predictions and show that the reform decreases the probability of going to disability benefits for individuals from age 40, although it slightly increases the probability of joining the disability rolls for younger individuals.

A number of recent papers have dealt with the effects of changes in disability insurance rules on the inflow into the disability system. For example, De Jong et al. (2011) analyze the effects of stricter screening of disability applicants in two out of the 26 Dutch regions. Their results show that the stricter screening implemented in these two regions led to a reduction in long-term sickness absenteeism as well as a decline in disability insurance applications. Similar results are obtained in the paper by Staubli (2011) for the case of Austria. In this case, the author analyzes a reform that increased the age at which conditions for disability insurance benefits are relaxed, from age 55 to age 57 for men. He applies a difference-in-difference model to find that enrollment to the disability system declined by 6 to 7.4 percentage points due to the policy change. Finally, the paper by Karlström et al. (2008) studies a reform of the Swedish disability insurance program that abolished special eligibility rules for workers aged 60 to 64 . Using also a difference-in-difference model they find a small reduction in the entrance in disability benefits after the reform but, as the change was announced two years before its implementation, they also report a strong anticipation effect of individuals entering the disability rolls the year before the policy came into effect. Another group of authors 
have focused on the effects of changes in the disability system on employment of disabled individuals or on the spillover effects of these reforms on other social security programs (see for example, Gruber (2000), Campolieti and Riddell (2011), Marie and Vall-Castello (2012), Gruber and Kubik (1997), Autor and Duggan (2003), Chen and Van Der Klaauw (2008) or Jimenez-Martin \& Vall-Castello (2009)). In our paper, we are interested on the effects of the reform on the inflow into the disability system as this was one of the aims of the reform (apart from reducing the total amount of benefits paid by the system).

The paper proceeds as follows: section 2 describes the specificities of the Spanish disability system. Section 3 describes the main change introduced by the reform in 2008 and section 4 presents some preliminary effects of the reform using aggregate data. Section 5 introduces the life-cycle model that has been designed to capture the incentives to apply to the disability benefits and presents the first quantitative results. In section 6 we present the diff-in-diff technique to estimate the effect of the 2008 policy reform in the calculation of the regulatory base of disability benefits and compare them with the effects of the policy in the theoretical model. Some conclusions are derived in the final part of the paper.

\section{THE DISABILITY SYSTEM IN SPAIN}

In Spain, there are two types of permanent disability benefits: i) contributory, which are given to individuals who have generally contributed to the Social Security system before the onset of the disabling condition; ii) and non-contributory, which are given to individuals who are assessed to be disabled but have never contributed to the Social Security system (or do not reach the minimum contributory requirement to access the contributory system). Non-contributory disability benefits are means-tested ${ }^{1}$ and managed at the regional level.

The size of the non-contributory system is relatively small compared to the contributory system $(197,126$ individuals received non-contributory disability benefits in 2009 , while 920,860 received contributory benefits during the same year). The amount of benefits received is also smaller in the non-contributory case (the average non-contributory pension is 417.09 Euros/month compared to an average contributory disability pension of 831.49 Euros/month). Furthermore, the change in 2008 affected only the contributory

\footnotetext{
${ }^{1}$ Income is evaluated yearly. The income threshold in 2010 was set at 4,755.80 Euros/year for an individual living alone. This amount is adjusted if the individual lives with other members.
} 
part of the system. For these reasons, in the remaining of the paper we focus only on the permanent contributory disability system in Spain.

The Social Security defines the permanent contributive disability insurance as the economic benefits to compensate the individual for losing a certain amount of wage or professional earnings when affected by a permanent reduction or complete loss of his/her working ability due to the effects of a pathologic or a traumatic process derived from an illness or an accident.

In order to capture the different situations in which a person can be after suffering from a disabling condition, the Spanish Social Security administration uses a classification of three main degrees of disability that depend on the working capacity lost ${ }^{2}$ :

(i) Partial disability: the individual is impaired to develop all or the fundamental tasks of his/her usual job or professional activity, but he/she is still capable of developing a different job or professional activity.

(ii) Total disability: the individual is impaired for the development of any kind of job or professional activity.

(iii) Severe Disability: Individuals who, as a result of anatomic or functional loses, need the assistance of a third person to develop essential activities of daily living such as eating, moving, etc...

\section{ELEGIBILITY AND PENSION AMOUNT BEDORE AND AFTER THE 2008 REFORM}

The eligibility requirements and the pension amount depend on the source of the disability (ordinary illness, work related or unrelated accident or occupational illness), the level of the disability and the age of the onset of the disability. Table 1 summarizes the main parameters of both the eligibility criteria and the pension formula. With respect to eligibility, the number of years of contributions required depends on the age of the onset of the disabling condition for common illness while there are no contributory requirements if the health impairment is due to either an accident or an occupational illness.

\footnotetext{
2 There is a fourth degree of disability benefits (permanent limited disability) but this type of benefits is already extinguished and it only consists on a one-time lump sum payment.
} 
The total amount of the pension is obtained by multiplying a percentage, which varies depending on the type of pension and the degree of disability (as shown in the last rows of Table 1) to the regulatory base, which depends on the source of the disability and on previous salaries ${ }^{3}$. The percentage is $55 \%$ or $75 \%$ for partial disability beneficiaries, $100 \%$ for total disability and $150 \%$ for severe disability. These percentages were not modified by the reform in 2008 .

The number of years included in the regulatory base depends on the source of the disability and, before the 2008 reform, for common illness the regulatory base was calculated by dividing by 112 the wage in the last 96 months ( 8 years) before becoming disabled. When the source of the disability is a work-unrelated accident, the regulatory base is calculated by dividing by 28 the wage in the last 24 months before becoming disabled. The individual can choose these 24 months from the last 7 years of work. For work-related accident or professional illness, the regulatory base is calculated by dividing by 12 the wage in the last 365 days before becoming disabled.

The reform of 2008 introduced a change in the way the regulatory base is calculated when the source of the disability is a common illness. That is, if the individual becomes disabled from 01-01-2008, the regulatory base is calculated by dividing by 112 the wage in the last 96 months ( 8 years) before becoming disabled (as before) but now this quantity is multiplied by a percentage that depends on the number of years contributed to the Social Security system. This percentage is the same used to calculate the old-age pension. The number of years from becoming disabled until reaching the normal retirement age (at age 65) will be counted as contributed to the system (in the remaining of the paper we call that number the "effective number of years contributed"=number of years contributed $+(65$-age $))$.

\footnotetext{
${ }^{3}$ Benefit $=$ Regulatory Base $*$ Percentage
} 
Table 1. Summary of the parameters to calculate permanent disability pensions before 2008

\begin{tabular}{|c|c|c|c|}
\hline & Ordinary Illness & $\begin{array}{l}\text { Work-unrelated } \\
\text { Accident }\end{array}$ & $\begin{array}{l}\text { Work-related } \\
\text { Accident or } \\
\text { Professional } \\
\quad \text { Illness } \\
\end{array}$ \\
\hline \multirow[b]{2}{*}{ Eligibility } & $\begin{array}{l}\text { Age }>=31 \text { : } \\
\text { Contributed } 1 / 4 \text { time } \\
\text { between } 20 \text { years old } \\
\text { and disabling condition. } \\
\text { Minimum of } 5 \text { years }\end{array}$ & \multirow{2}{*}{$\begin{array}{l}\text { No minimum } \\
\text { contributory } \\
\text { period required }\end{array}$} & \multirow{2}{*}{$\begin{array}{l}\text { No minimum } \\
\text { contributory } \\
\text { period required }\end{array}$} \\
\hline & $\begin{array}{l}\text { Age }<30 \text { : } \\
\text { Contributed } 1 / 3 \text { time } \\
\text { between } 16 \text { years old } \\
\text { and disabling condition. } \\
\text { No minimum number of } \\
\text { years required }\end{array}$ & & \\
\hline $\begin{array}{l}\text { Regulatory } \\
\text { Base }\end{array}$ & $\begin{array}{l}\text { Average wage last } 8 \\
\text { years of work }\end{array}$ & $\begin{array}{l}\text { Average annual } \\
\text { wage of } 24 \\
\text { months within the } \\
\text { last } 7 \text { years of } \\
\text { work }\end{array}$ & $\begin{array}{l}\text { Average wage } \\
\text { last year of work }\end{array}$ \\
\hline \multirow{3}{*}{$\begin{array}{l}\text { Percentage } \\
\text { applied to the } \\
\text { regulatory base }\end{array}$} & \multicolumn{3}{|c|}{$\begin{array}{l}\text { Partial Disability: } 55 \% \\
\text { Individuals older than } 55 \text { with difficulties to find a job due to lack } \\
\text { of education or characteristics of the social and labor market of } \\
\text { the region where they live: } 75 \%\end{array}$} \\
\hline & \multicolumn{3}{|l|}{ Total Disability: 100\% } \\
\hline & \multicolumn{3}{|c|}{ Severe Disability: $100 \%+50 \%$} \\
\hline
\end{tabular}

Table 2. Change in the regulatory base for ordinary illness introduced by the reform in 2008

\begin{tabular}{|l|l|l|}
\hline & \multicolumn{1}{|c|}{$\begin{array}{c}\text { Ordinary Illness BEFORE } \\
\text { REFORM }\end{array}$} & \multicolumn{1}{c|}{$\begin{array}{c}\text { Ordinary Illness AFTER } \\
\text { REFORM }\end{array}$} \\
\hline Regulatory Base & $\begin{array}{l}\text { Average wage last 8 years of } \\
\text { work }\end{array}$ & $\begin{array}{l}\text { Average wage last 8 years of } \\
\text { work*PERCENTAGE }\end{array}$ \\
\hline $\begin{array}{l}\text { Percentage applied } \\
\text { to the regulatory } \\
\text { base }\end{array}$ & It is the same before and after the reform; see table 1 above. \\
\hline
\end{tabular}

If the individual has less than 15 years contributed the percentage is $50 \%$. If the individual has more than 15 years of contributions, the percentage applied to the regulatory base is the following: 
Table 3. Percentage applied to the regulatory base for ordinary illness introduced in 2008

\begin{tabular}{|l|l|}
\hline $\begin{array}{l}\text { Effective Number of } \\
\text { Years Contributed }\end{array}$ & $\begin{array}{l}\text { Percentage applied to the regulatory } \\
\text { base }\end{array}$ \\
\hline 15 & $50 \%$ \\
\hline 16 & $53 \%$ \\
\hline 17 & $56 \%$ \\
\hline 18 & $59 \%$ \\
\hline 19 & $62 \%$ \\
\hline 20 & $65 \%$ \\
\hline 21 & $68 \%$ \\
\hline 22 & $71 \%$ \\
\hline 23 & $74 \%$ \\
\hline 24 & $77 \%$ \\
\hline 25 & $80 \%$ \\
\hline 26 & $82 \%$ \\
\hline 27 & $84 \%$ \\
\hline 28 & $86 \%$ \\
\hline 29 & $88 \%$ \\
\hline 30 & $90 \%$ \\
\hline 31 & $92 \%$ \\
\hline 32 & $94 \%$ \\
\hline 33 & $96 \%$ \\
\hline 34 & $98 \%$ \\
\hline 35 & $100 \%$ \\
\hline
\end{tabular}

This was the main change introduced by the reform in 2008.

The income tax rules were not modified by the reform in 2008 and differ across disability types. Partial disability benefits are taxable under the general income tax rules, while total disability pensions are always exempted from income taxes. Furthermore, if the individual works while receiving the pension, there is a reduction in the earnings used to calculate the income tax of 2,800 Euros/year if their degree of disability is low (between 33\% and 65\%) and of 6,200 if the disability level is higher (more than 65\%) or if the disabled has reduced mobility. In addition, individuals receiving partial disability benefits can combine the benefits with earnings from work, as long as the type of job is compatible with his/her disability.

In general, to be granted a permanent disability benefit, the individual must come from a situation of sick leave (also called temporary disability/incapacity) and be observed as still presenting anatomic or functional reductions that decrease or cancel his/her capacity to work after following the prescribed medical treatment. The application can be started by the provincial office of the National Institute of Social Security (NISS), by 
the institutions that collaborate in the process (such as hospitals), or by the individual himself (in which case, more documentation is required). The Disabilities Evaluation Team evaluates the medical report and the professional background of the applicant and, on the basis of this analysis, the directors of the provincial office of the NISS decide on the type of disability pension granted (if any), the benefit level and the date of the next medical check-up. All permanent disability pensions are automatically converted to old-age pensions once the individual turns sixty-five ${ }^{4}$.

\section{EFFECT OF THE REFORM: AGGREGATE DATA}

We expect the reform to reduce the incentives to apply for disability benefits for individuals who do not reach the 35 years of contributions. For individuals with 35 years of contributions the incentives are unchanged as they receive a $100 \%$ of the regulatory base (average wage of the last 8 years) both before and after the reform.

However, for individuals with less than 35 years of contributions, if they fulfilled the eligibility conditions (which are not changed), they could receive as a regulatory base the average wage of the last 8 years of work before the reform whereas now there is a percentage which depends on the number of effective years contributed that reduces the regulatory base to calculate the benefit.

In order to get a first impression on the existence or not of a disincentive effect to apply to the benefits after the reform, we show in figure 1 aggregate data on the percentage growth in the number of disability benefits with respect to the previous year.

\footnotetext{
${ }^{4}$ Most of the outflows from the permanent disability system are due to death or automatic transfer to old-age pensions. Around $4 \%$ of the outflows are due to improvement of the health condition and $2.7 \%$ to a judicial process. Monthly outflows in 2010 were around 2,500-3,000.
} 
Figure 1. Percentage of growth in the number of contributory disability benefits with respect to the previous year.

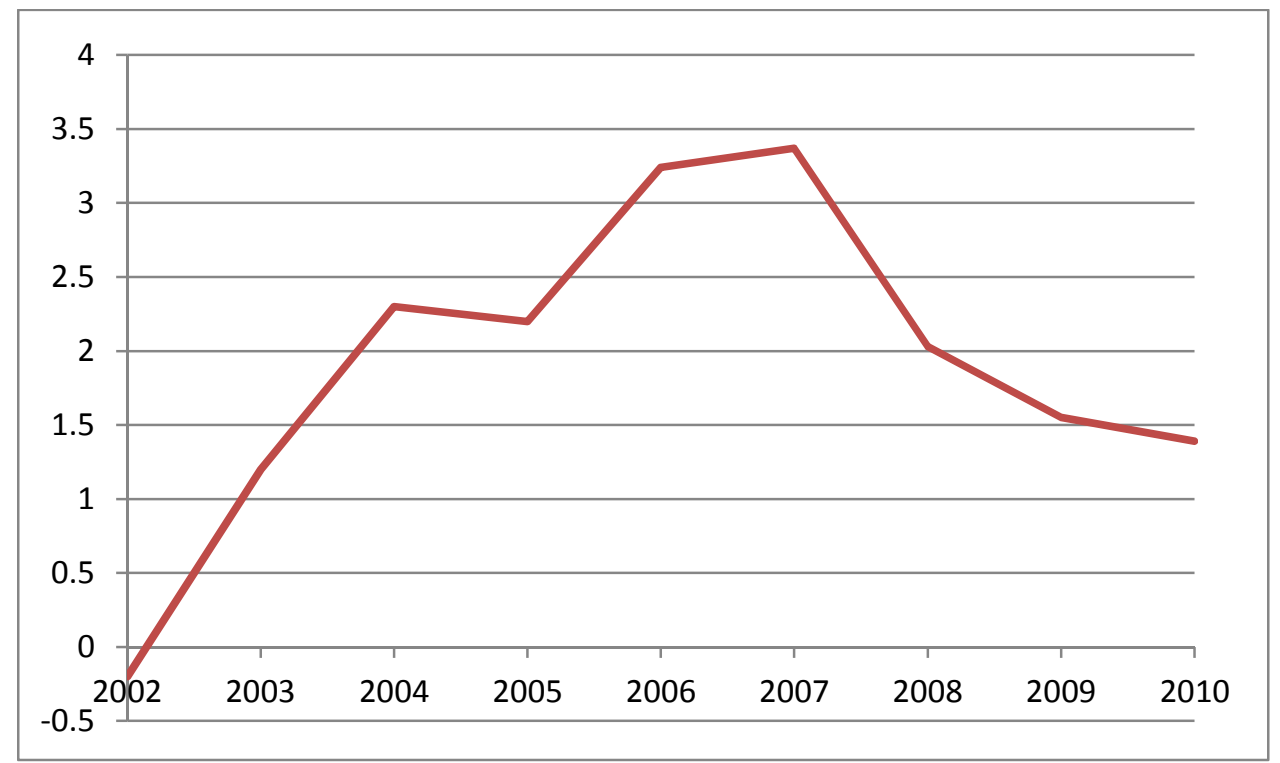

We can see in figure 1 a change in the tendency to increase and a strong drop in the growth of the number of disability benefits from 2008 onwards.

Therefore, this first evidence seems to point to the existence of an effect of the 2008 reform although it can be argued that the timing coincides with the economic crisis that hit Spain from 2008.

Figure 2 shows the annual growth in the GDP in Spain and we can observe that, even if the GDP dropped in the mid-2008, the evolution of the GDP does not seem to be that closely related to the evolution of the growth in the disability system. 
Figure 2. Annual GDP growth in Spain, 2001-2011.

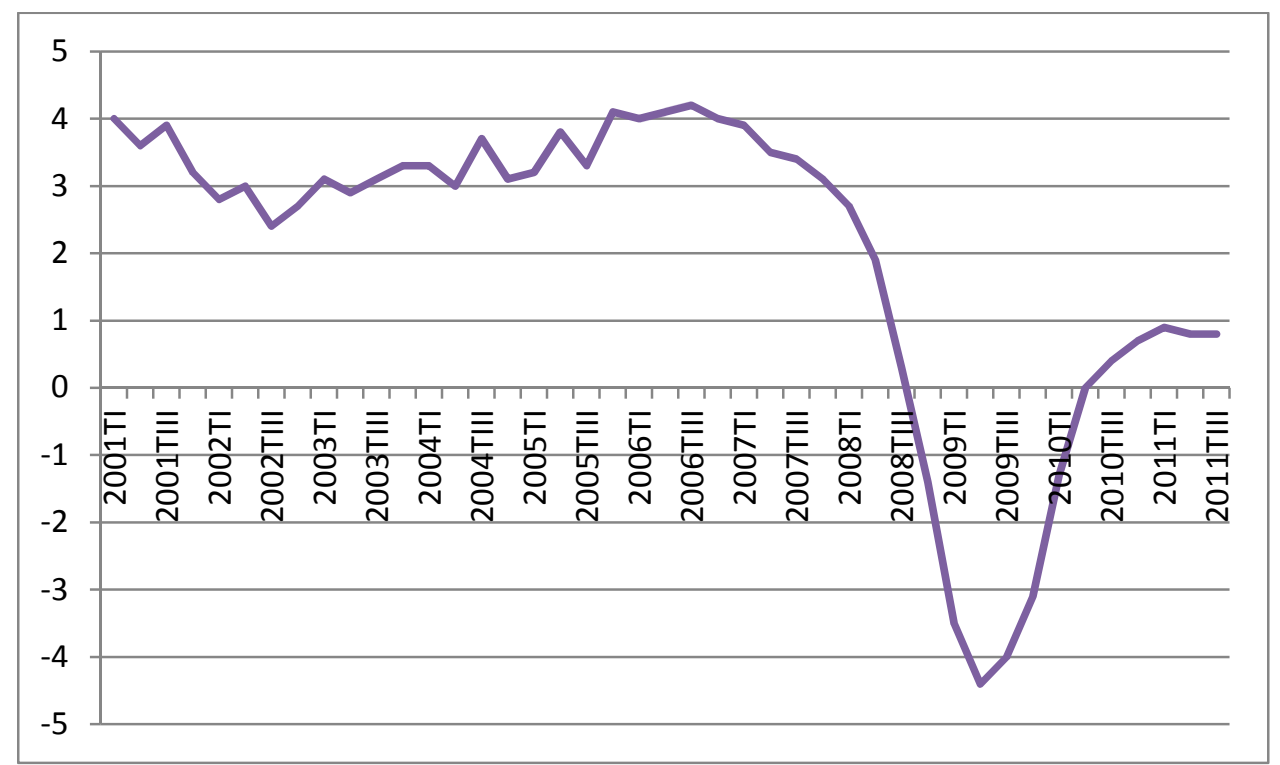

Furthermore, in order to disentangle the effect of the reform in 2008 from the other confounding factors, like the business cycle, that can have an effect on the decision to apply or not to disability benefits, we will estimate a diff-diff model using a large administrative dataset, the MCVL, that will allow us to distinguish between the control (not affected by the reform because they have already contributed 35 years) and treatment group (affected by the reform because they have contributed less than 35 years) while controlling for a number of personal, regional and business-cycle variables. In principle, the economic crisis should have the same effect on both the control and treatment group. Including the GDP growth in our regressions we will be able to control for the effect of the economic crisis on the inflow into disability benefits and to isolate and identify the effect of the reform on the treatment group. The final aim of the paper is to identify and quantify the effect of the 2008 reform on incentives and disincentives of individuals to apply to the disability system.

\section{SIMULATED SCENAROPS BEFORE AND AFTER THE 2008 REFORM}

In this section we introduce a theoretical model in order to simulate changes in the incentives to apply to disability benefits for individuals before and after the introduction of the 2008 reform. To this end, we first calibrate the model at annual frequencies just before the reform. Then we depart from the initial setup by reproducing the observed changes in the way the regulatory base is calculated introduced in 2008 . The simulated 
results complement the estimated effects presented in section 6 by predicting the impact of the reform on the probability of becoming disabled.

\subsection{The model before the reform}

We consider a life cycle setting for partially disabled individuals characterized by a deterministic age, $i$, between 25 and 59 years old. An individual becomes disabled at each age with probability $\mu_{i}$. Then, a disabled person can either be officially disabled receiving disability benefits $(d)$ or not $(n)$. The non-officially disabled individual is working and must decide to apply to the $d$-status. We assume that non-officially disabled workers have a specific productivity level, $z_{i}$, which is independent and identically distributed across age, with cumulative distribution function $F\left(z_{i}\right)$ and support $\left[0, z^{\max }\right]$. Thus, the wages of this type of workers have both an idiosyncratic, $z$, and an aggregate component, $w_{i}^{n}$. Moreover, due to the disability condition, there is a cost of working $C_{i}$. This cost does not only capture the labor mobility costs but also the productivity gap with respect to the non-disabled status.

Since the officially disabled person cannot work in his former job, he has to search for a new one. The individual discounts future payoffs at a common rate $\beta$, time is discrete and the economy is at the steady-state. All individuals who are officially disabled receive a pension equivalent to a proportion, $\alpha_{i}$, of their average wage for the years previous to becoming disabled, $\bar{w}_{i}$. When a disabled person is not working he/she enjoys an unemployment income $\rho w_{i-1}^{n}$ each period, where $\rho$ is the replacement rate over the labor income before becoming disabled, $w_{i}^{n}$. This income has to be given up when the officially-disabled person finds a job. Each age, a non-employed individual finds a job with probability, $\lambda_{i,}$. After finding a job, the worker receives a wage, $w_{i,}^{d}$. Finally, officially disabled workers separate from their jobs with probability $\gamma_{i}$ per age.

Denoting the individual's value of being not officially disabled, $W_{i,}^{n}$ the workers' values of being officially disabled but non-employed or employed as $U_{i}^{d}$, and $W_{i}^{d}$, respectively, the following Bellman equations describe the model:

$$
W_{i}^{n}(z)=z_{i} w_{i}^{n}-C_{i}+\beta\left[\int_{z_{i+1}^{R}}^{z^{\max }} W_{i+1}^{n} d(\varepsilon)+F\left(z_{i+1}^{R}\right) U_{i+1}^{d}\right]
$$




$$
\begin{gathered}
U_{i}^{d}=\rho w_{i}^{n}+\alpha_{i} \bar{w}_{i}+\beta\left[\lambda_{i} W_{i+1}^{d}+\left(1-\lambda_{i}\right) U_{i+1}^{d}\right] \\
W_{i}^{d}=\alpha_{i} \bar{w}_{i}+w_{i}^{d}-C_{i}+\beta\left[\gamma_{i} U_{i+1}^{d}+\left(1-\gamma_{i}\right) W_{i+1}^{d}\right]
\end{gathered}
$$

At the beginning of each new age, $i+1$, a job productivity, $z$, is drawn in the general distribution $F(z)$ with $\left[0, z^{m a x}\right]$. Individuals decide to become officially disabled if, for a given threshold level $z_{i}^{R}$, the present-discounted return of being non-officially disabled, $W_{i}^{n}\left(z_{i}^{R}\right)$, is lower than the present-discounted return of being officially disabled, $U_{i}^{d}$. Formally, the participation rule is

$$
W_{i}^{n}\left(z_{i}^{R}\right)=U_{i}^{d}
$$

where $\mu_{i} F\left(z_{i+1}^{R}\right)$ is the probability of becoming officially disabled at age $i+1$.

\subsection{Calibration and simulation}

We calibrate this life cycle model during the four years before the 2008 reform for all disabled workers (2004-2007). The wages $w_{i}^{n}$ represent the average labor income during the year before becoming disabled at each age $i$, while $w_{i}^{d}$ is the average labor income after becoming disabled. Both series are taken from the Continuous Sample of Working Lives ("Muestra Continua de Vidas Laborales", MCVL). The regulatory base for the disability benefits $\bar{w}_{i}$, is also taken from the MCVL. The three income series have been detrended using the HP filter with smooth parameter 100 and divided by the 25 years old average wage of a non-officially disabled, $w_{25}^{n}$. Thus, all sources of the life cycle income are expressed in terms of the wage of the youngest individual. Figure 3 shows the three life cycle series. There is a wage gap between non-disabled and disabled workers, which increases until the age of 50 years old and then it remains constant around 67.5 percent. In turn, the average regulatory base is somewhat higher than the wage before disability for individuals below 28 years old but it becomes lower after that age with a maximum gap of 20 percent at 50 years old. 
Figure 3 Wages before and after of becoming disabled and regulatory base

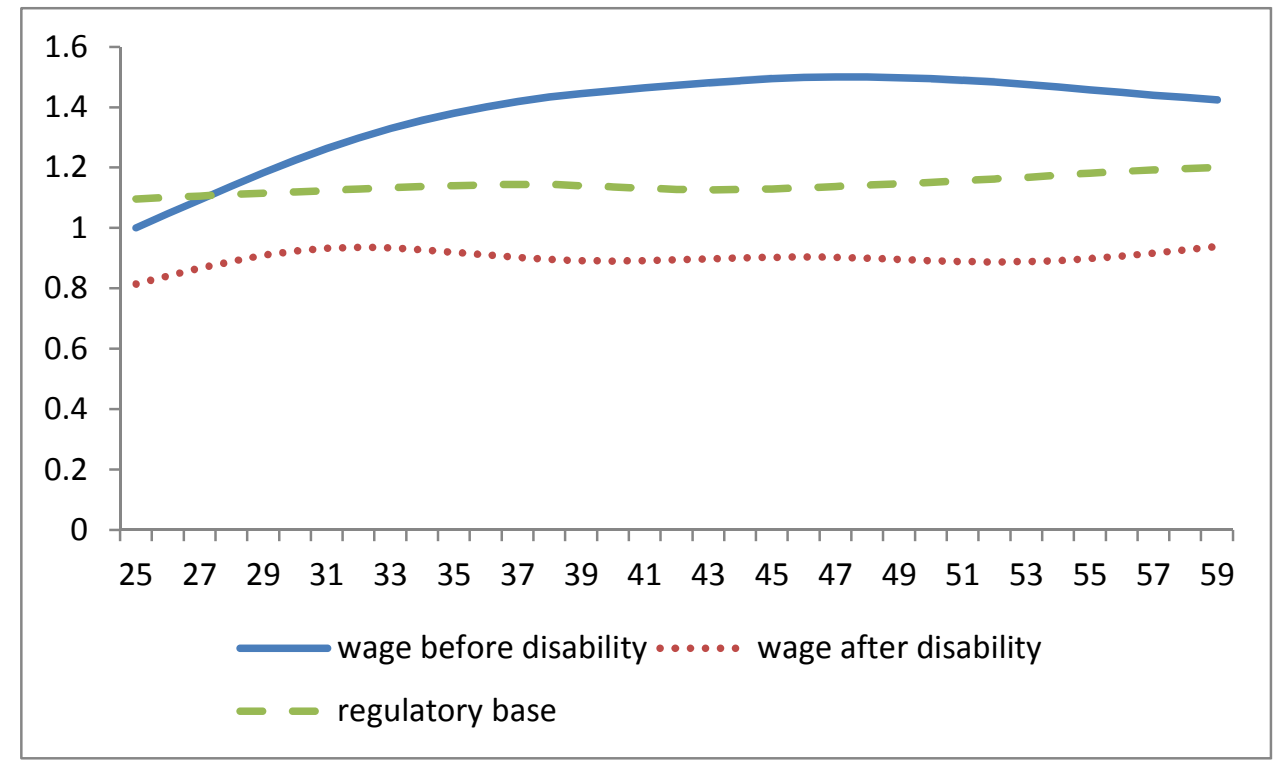

We calculate the HP detrended average job finding and job destruction rates of disabled individuals at each age $i$ using data from the MCVL. As you can see in Figure 4, the job finding rate decreases with age while the opposite occurs to the job separation rate.

Silva and Vall (2012) estimate a log-normal distribution for the wage of disabled individuals in Spain with standard deviation, $\sigma=0.13$. We assume that the normalized idiosyncratic productivity $z$ has the same distribution and standard deviation. Moreover, we set the discount factor at $\beta=0.96$, which implies a reasonable interest rate of nearly 4 percent. From the MCVL for individuals receiving permanent disability benefits, we set the average net replacement rate at $22 \%, \rho=0.22$. Using data from the 2008 EDAD Survey, we calculate the proportion of individual who report a level of disability that affects their working capacity at each age, $\mu_{i}$. 
Figure 4 Job separation and job finding rates

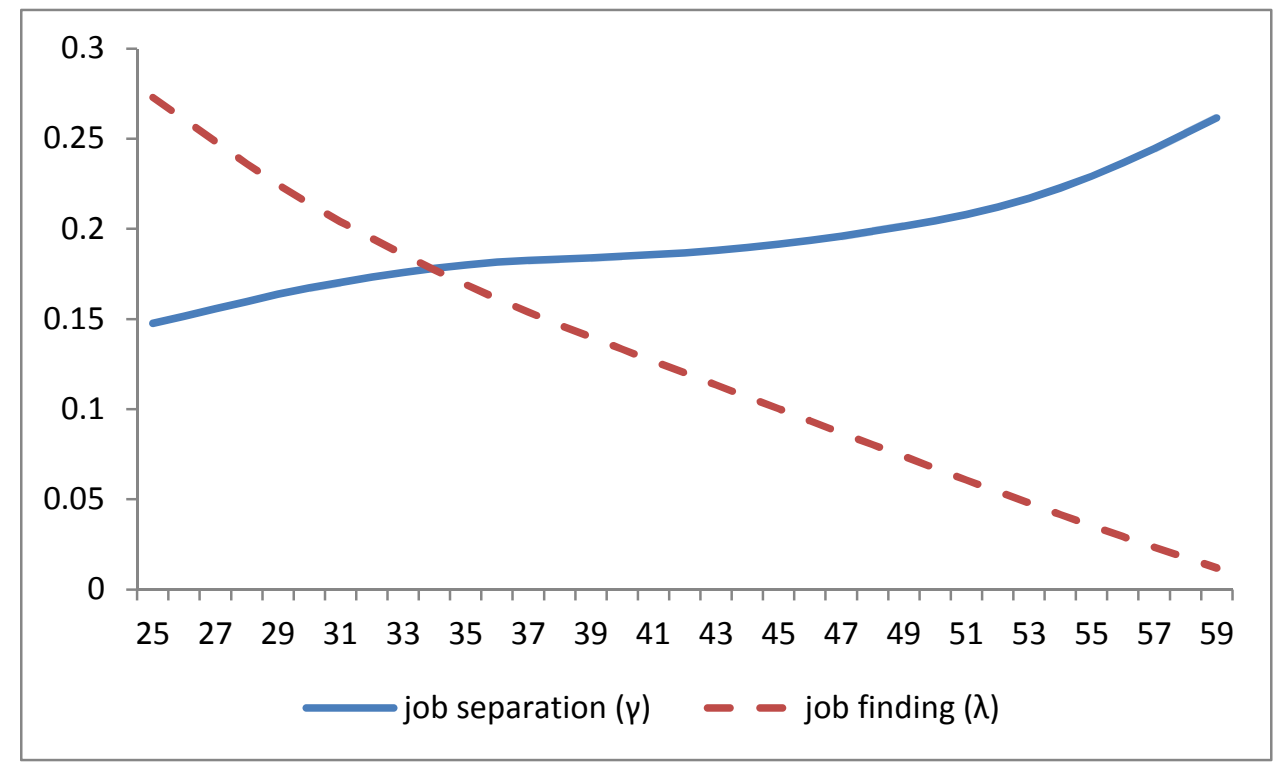

Individuals in the partial disability scheme receive $55 \%$ of the regulatory base until 54 years old (which is an average of their last salaries). This 55\% can be increased to $75 \%$ for individuals aged 55 or more. However, when defining the compatibilities of the receipt of this increase in the benefits, the legislation stresses that if the individual starts working while receiving the $75 \%$, he will have to report it to the Social Security Administration and the $20 \%$ increase will be suspended until he stops working. Thus, we set $\alpha_{i}$ at 0.55 for all individuals below 55 years old and $\alpha_{i}=0.75$ for non-employed disabled individuals above that age.

Since we do not have information on the working costs for a disabled individual, we assume that these costs are equivalent to an amount proportional to the level of disability multiplied by the labor income before receiving the disability benefits. In Spain, partial disability represents a reduction of between $33 \%$ and $65 \%$ of the working ability and we set it at the lower bound value of $33 \%$. Thus, the working disability costs at each age are $C_{i}=0.33 w_{i}^{n}$.

Finally, the values of $W_{i}^{n}, U_{i}^{d}, W_{i}^{d}$ and the reservation wages $z_{i}^{R}$ are calibrated by solving simultaneously equations (1)-(4) at each age. Figure 5 shows the simulated probabilities of becoming officially disabled at age $i+1, \mu_{i} F\left(z_{i+1}^{R}\right)$. The first important result is that this probability increases with age, especially after the 33 years old. A special mention deserves the jump on the probability of becoming officially disabled from 0.005 at 54 to 0.03 at 55 years old. This result takes place due to the increase of 20 
percentage points in the regulatory base (from $55 \%$ to $75 \%$ at 55 years old) which generates a strong incentive to apply to the disability status.

Figure 5. Probability of becoming officially disabled

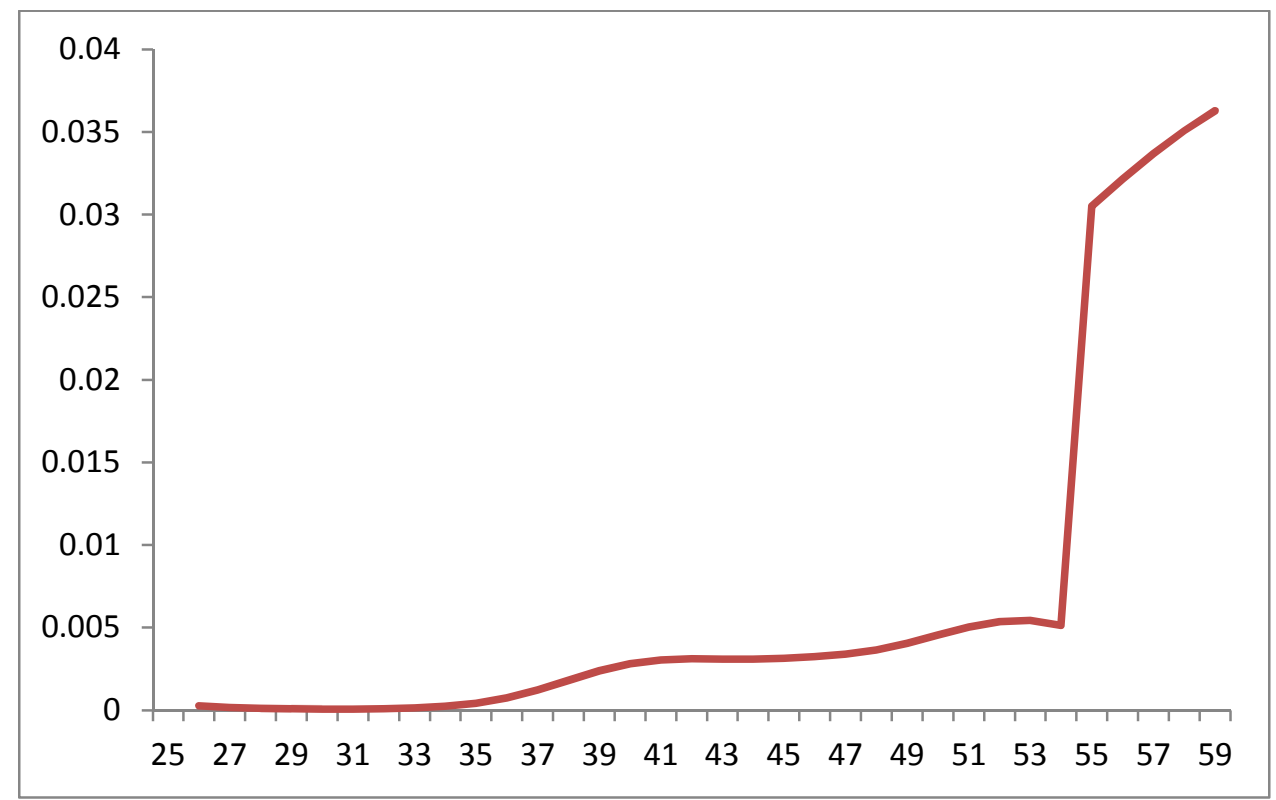

\subsection{The 2008 the reform}

As we mentioned before, the main change of the 2008 reform was a change in the way the regulatory base is calculated. Thus, from January 2008 , the regulatory base, $\alpha_{i} \bar{w}_{i}$ is now multiplied by a percentage $\theta_{i, j}$ that depends on the effective number of years contributed to Social Security system (SS). This number is equal to the number of years contributed to the system, $j$, plus the difference between 65 years old and the age at which the individual becomes disabled, $i$. For example, the effective number of years contributed to the SS system for an individual with 10 working years and 35 years old is $10+(65-35)=40$. Using data from the MCVL we take the average $j$ at each age $i$ to calculate the detrended $\theta_{i, j}$ between 25 and 59 years old. Table 4 shows the calculated percentage $\theta_{i, j}$.

Finally, we keep unchanged the rest of parameters and income series before the reform and simulate the impact of the change in the adjusted regulatory base on the probability of becoming officially disabled at each age, $\mu_{i} F\left(z_{i+1}^{R}\right)$. Figure 6 compares the simulated probabilities before and after the reform. According to the model, the reform has reduced the incentives to apply to disability benefits for partially disabled individuals who do not reach the 35 years of contributions. The affected age groups of individuals 
are, in average, those with more than 45 years old. For example, for the group of individuals between 55 and 59 years old, the probability of becoming officially disabled was reduced between $25 \%$ and $34 \%$ after the reform. In contrast, for individuals with 35 or more effective years of contributions the incentives have been unchanged because they still receive a $100 \%$ of the regulatory base (see Table 4 ).

Table 4. Calculated percentage applied to the regulatory base for each age

\begin{tabular}{|c|c|c|}
\hline Age $i$ & $\begin{array}{l}\text { Average Effective Contributed } \\
\text { Years, } j+(65-i)\end{array}$ & $\begin{array}{l}\text { Percentage applied to the } \\
\text { regulatory base } \theta_{i, j}\end{array}$ \\
\hline 25 & 44 & $100 \%$ \\
\hline 26 & 44 & $100 \%$ \\
\hline 27 & 44 & $100 \%$ \\
\hline 28 & 43 & $100 \%$ \\
\hline 29 & 43 & $100 \%$ \\
\hline 30 & 42 & $100 \%$ \\
\hline 31 & 42 & $100 \%$ \\
\hline 32 & 41 & $100 \%$ \\
\hline 33 & 41 & $100 \%$ \\
\hline 34 & 40 & $100 \%$ \\
\hline 35 & 40 & $100 \%$ \\
\hline 36 & 39 & $100 \%$ \\
\hline 37 & 39 & $100 \%$ \\
\hline 38 & 38 & $100 \%$ \\
\hline 39 & 38 & $100 \%$ \\
\hline 40 & 37 & $100 \%$ \\
\hline 41 & 36 & $100 \%$ \\
\hline 42 & 36 & $100 \%$ \\
\hline 43 & 35 & $100 \%$ \\
\hline 44 & 35 & $100 \%$ \\
\hline 45 & 34 & $98 \%$ \\
\hline 46 & 33 & $96 \%$ \\
\hline 47 & 32 & $94 \%$ \\
\hline 48 & 32 & $94 \%$ \\
\hline 49 & 31 & $92 \%$ \\
\hline 50 & 30 & $90 \%$ \\
\hline 51 & 29 & $88 \%$ \\
\hline 52 & 29 & $88 \%$ \\
\hline 53 & 28 & $86 \%$ \\
\hline 54 & 27 & $84 \%$ \\
\hline 55 & 26 & $82 \%$ \\
\hline 56 & 25 & $80 \%$ \\
\hline 57 & 24 & $77 \%$ \\
\hline 58 & 23 & $74 \%$ \\
\hline 59 & 22 & $71 \%$ \\
\hline
\end{tabular}


Figure 6. Probability of becoming officially disabled before and after the reform

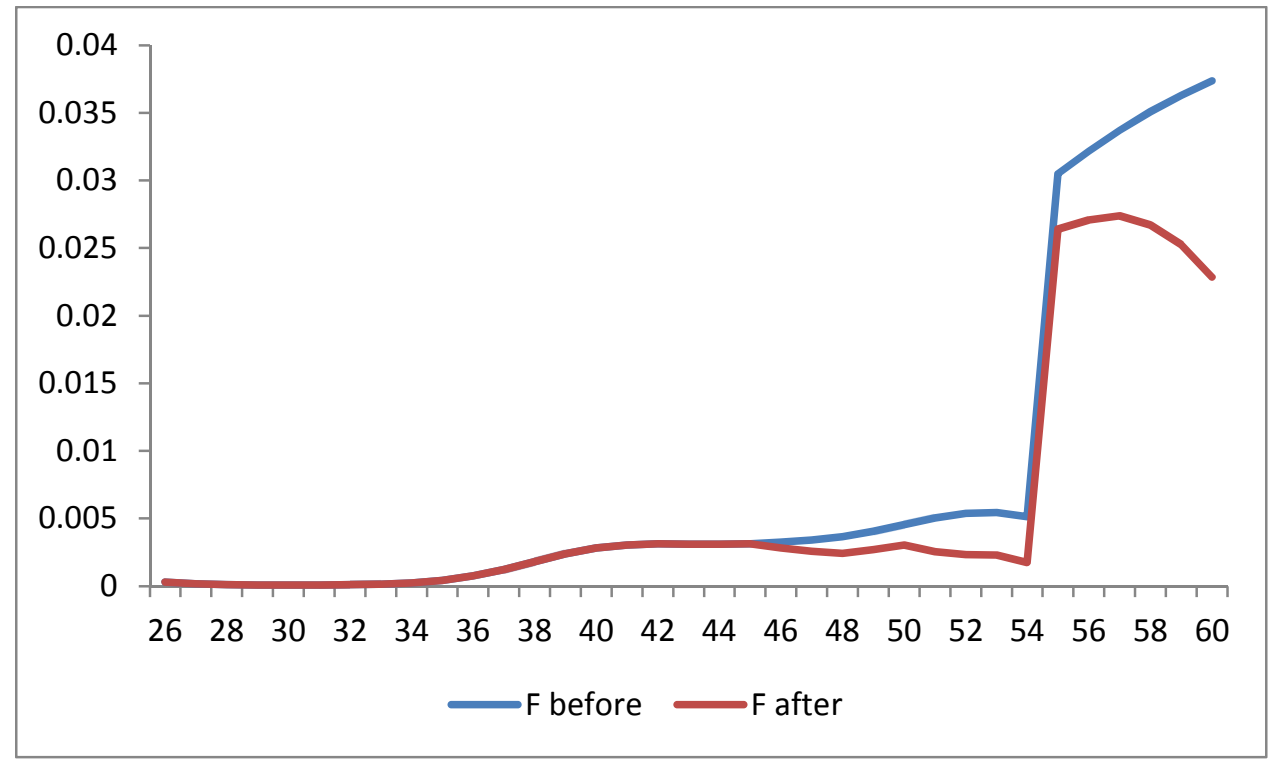

\section{EMPIRICAL ESTIMATION OF THE EFFECTS OF THE REFORM}

Next, we estimate the effect of the policy reform in 2008 on the inflow into disability benefits in Spain. Our empirical approach is based on a difference-in-difference model in which we exploit the fact that, for some individuals, the policy in 2008 did not change the calculation of the regulatory base. In particular, our control group is formed by individuals for which the new rule to calculate the number of effective contributed years results in 35 years contributed. These individuals will get a $100 \%$ of the regulatory base (their $\theta_{i, j}$ is $100 \%$ ) under the new scenario, exactly the same than before the reform, when the number of years contributed to the system was not taken into account to calculate the regulatory base of disability benefits ${ }^{5}$. Alternatively, the individuals that were affected by the reform constitute our treatment group. That is individuals that do not reach the 35 years of effective contributions after the reform for which the regulatory base will be multiplied by a percentage of less than $100 \%$ after 2008.

\footnotetext{
${ }^{5}$ There could be another potential control group formed by individuals that enter the disability System due to a working accident, as these group of workers are also not affected by the reform. However, from a total of 11.656 individuals entering disability in our sample, only 1392 are due to a working accident. Furthermore, we would not have a way to classify the individuals into a control or treatment group until they enter the disability scheme. As we model the entrance into disability benefits, we have a large group of individuals that never enter the System and that could not be classified into control/treatment group.
} 


\subsection{Database and sample selection}

The study will use the Continuous Sample of Working Lives ("Muestra Continua de Vidas Laborales", MCVL) which is a microeconomic dataset based on administrative records provided by the Spanish Social Security Administration. It contains a random sample of $4 \%$ of all the individuals who, at some point during 2010 , had contributed to the social security system (either by working or being on an unemployment scheme) or had received a contributory pension. The random sample selected contains over one million people.

There is information available on the entire employment and pension history of the workers, including the exact duration of employment, unemployment and disability pension spells, and for each spell, several variables that describe the characteristics of the job or the unemployment/disability benefits. There is also some information on personal characteristics such as age, gender, nationality and level of education. The macroeconomic variables used to capture the economic business cycle are derived from the Spanish "Instituto Nacional de Estadistica".

We select a sample of all individuals that are observed as not being in the disability rolls between 2004 and 2010 and we evaluate whether they move to disability benefits or not each year. Therefore, we model transitions from a situation of non-disability (ND) to a situation of disability (D). We do not take into account whether individuals are employed, unemployed or inactive before joining the disability rolls in an attempt to keep the model simple and reach our goal of evaluating the effects of the change in the way to calculate the regulatory base introduced in 2008 on the entrance into disability benefits. As in the theoretical model, we include individuals aged 20 to 59 years old in our sample period. The selected sample contains 911.898 individuals in our sample (5.421.319 person-year observations in total), 504.788 of them are men while 407.110 are women. 11.656 of all individuals in our sample move to disability benefits at some point between 2004 and 2010.

\subsection{Difference-in-Difference Model}

We use a diff-in-diff technique to estimate the effect of the 2008 policy reform in the calculation of the regulatory base of disability benefits. As mentioned before, we use as control group individuals that had a sufficient number of effective contributed years, 35 
years, so that the reform did not change their regulatory base. That is, we use as a control group the individuals for which $\theta_{i, j}$ is $100 \%$ after the reform. Therefore, for each individual at each age, we calculate the number of effective contributed years using the number of years contributed to the system and the number of years remaining to reach the age of 65 years old and classify him/her in the control group if the number of effective contributed years is 35 or more. The individual belongs to the treatment group if the reform had an effect on the way that his regulatory base was calculated. This will happen if the number of effective years contributed is less than 35 . If that is the case, he/she would get a $100 \%$ of the regulatory base before the reform and a lower percentage after the reform.

Our empirical model is based on the following equation (we have supressed the time subscripts for simplicity):

$$
Y=\alpha+\beta_{1} \text { Treatment }+\beta_{2} \text { After }+\beta_{3} \text { Treatment } * \text { After }+X^{\prime} \beta_{4}+\varepsilon
$$

Where $Y$ is the probability that an individual enters the disability rolls. Therefore, $Y$ is a dummy variable that equals one if the individual is observed as being on the disability rolls in year $t$ but not in year $t-1$, and is zero otherwise. Treatment equals one if the individual is affected by the policy change, that is, if the individual has less than 35 effective years contributed. Treatment equals zero if the individual is not affected by the policy (has 35 or more effective years contributed). After equals one for the years after the policy change $(2008,2009$ and 2010) and zero for the years prior the legislative change (2004, 2005, 2006 and 2007). As the policy came into effect on $1^{\text {st }}$ January 2008, we include 2008 in the post-policy period. Treatment*After is the interaction term that captures the effect of the policy change. $X$ is a vector of individual and business cycle controls (whether the individual was self-employed before joining the disability rolls, whether is a female or a male, the skill level (which is a proxy for education), one dummy for each of the 17 autonomous communities in Spain and the GDP growth of the country for each year included in the sample). Finally, $\varepsilon$ is an error term. Therefore, the interaction term captures whether there were any changes in the behavior of individuals affected by the policy change relative to the control group, which was not affected by the policy. We want to understand whether the group of individuals affected by the policy had a lower incentive to join the disability rolls as the amount of benefits 
that they would receive after the change is lower than the one they would have received before the policy change.

We compute the standard errors for our estimated clustering at the individual level in all our regressions.

\subsection{Results}

Tables 1 and 2 in the appendix present the results for the probability of entering the disability rolls. Table 1 reports the results of a logit and a linear probability model that only include the policy variables and no covariates. Both models show a negative and very significant coefficient for the diff-in-diff estimate, that is the Treatment*After variable. This negative coefficient indicates that the introduction of the policy change in 2008 did have an effect in decreasing the incentives to join the disability rolls for the group of individuals affected by the policy change due to the lower amount of disability benefits that they would get after the reform. The results do not change when we include the covariates in both models and we can see in Table 2 that the results for the diff-indiff coefficient are still negative and very significant.

In order for these diff-in-diff estimates to be reliable, a common trend assumption must be satisfied for the period before the policy change. We can see in Figure 7 that this is the case for our estimates. In that figure, we can see that the predicted probability of entering the disability rolls follows a very similar path for the control and treatment group before the policy change came into effect in 2008. This is reassuring for our results and confirms that the common trend assumption is satisfied. Figure 6 also shows that once the policy was introduced, the probability of entering the disability rolls is reduced for the treated group while it slightly increases for the control group. 
Figure 7. Predicted probability of entering the disability rolls: treated-control groups.

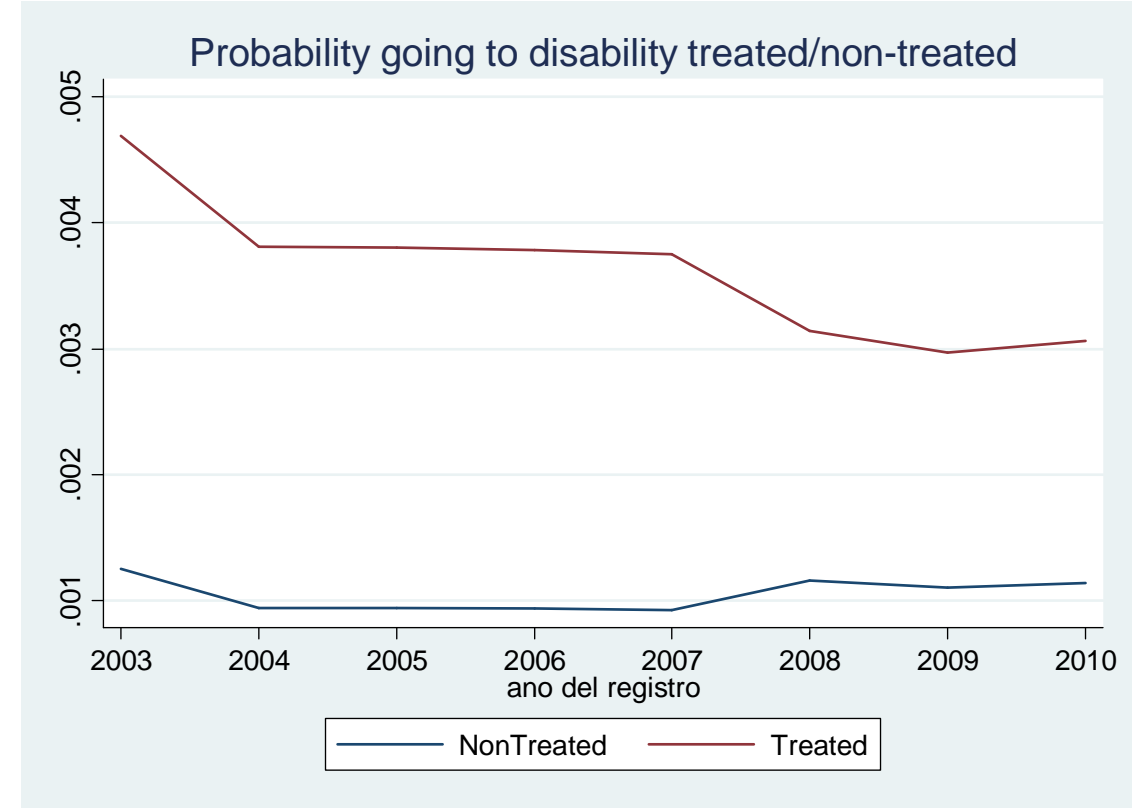

6.4. Comparing the effects of the policy in the theoretical/empirical model

Figure 8 plots the probability of entering the disability rolls before and after the reform by age predicted after the estimation of the empirical model (logit). In this figure we can observe that the reform slightly increases the probability of joining the disability rolls for younger individuals while it decreases the probability of going to disability benefits for individuals from age 40 . The drop in the probability increases with age and so the increase in the probability of going to disability benefits at age 55 (due to the increase in the benefits) is softened after the reform. This is a very similar effect of the reform than the one obtained in the theoretical model. In figure 6, we can see that the theoretical model predicts a drop in the probability of applying to disability benefits from age 44 onwards and that the increase of the probability at age 55 is also softened after the reform.

The only difference is that the theoretical model does not predict the moderate increase in the probability of joining the disability rolls for individuals before age 30 that we observe in the predictions of the empirical model. Remember that, in the theoretical model, the representative individuals between 25 and 44 years old have an average of effective contributed years above 35 , implying that they receive $100 \%$ of the percentage applied to the regulatory base (see Table 4). Thus, they represent the control group of the simulated model. In contrast, individuals above 44 years old display less than 35 
years of effective contributions. This second group corresponds to the treated group in our simulated results. In contrast, and due to the heterogeneity of our sample data, in the empirical model we observe both control and treated individuals at each age.

Figure 8. Predicted probability of joining the disability rolls before-after the reform.

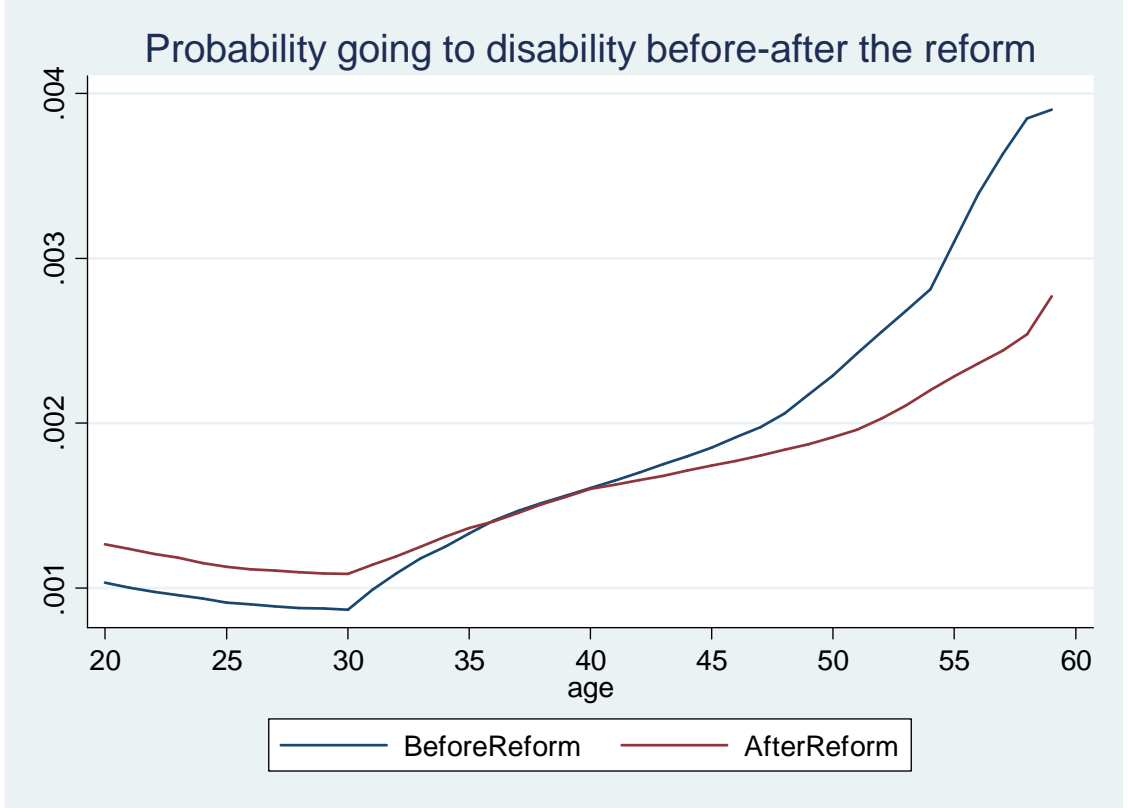

To compare the magnitude of the impact of the reform on the probability of becoming disabled in both the theoretical and the empirical model, Figure 8 shows the ratio between the probabilities of going to disability After/Before the reform.

Figure 9. Relative ratio of the probabilities of becoming disabled After/Before the reform

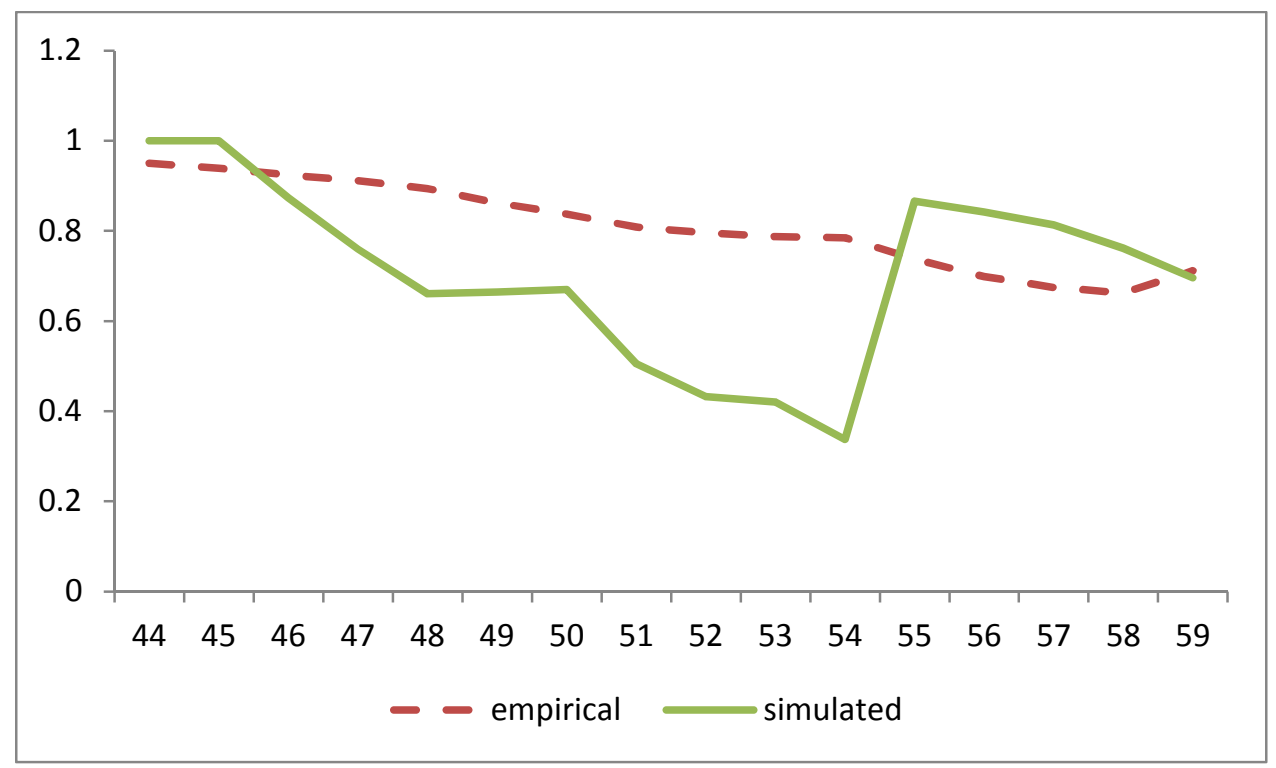


As you can see, both models display an important reduction in that ratio (between $10 \%$ and $60 \%$ depending on the age). However, the decrease in the ratio is much higher in our theoretical model for the group of individuals between 46 and 54 years old.

\section{THE EFFECTS OF THE REFORM FOR TOTALLY DISABLED INDIVIDUALS}

Finally, as the change in the way to calculate the regulatory base introduced in 2008 was also applied to individuals entering the total disability system (not only partially disabled individuals), we estimate the same empirical model for totally disabled individuals in order to see if the disincentive effect to join the disability rolls was also present for this group of workers. We can see in table 3 and 4 in the appendix that the results are almost the same for partially than for totally disabled individuals. There exists also a disincentive to join the disability rolls for individuals that have contributed less than 35 effective years after the policy was implemented in 2008.

Similarly, figure 10 shows that the disincentive is very similar to the one for partially disabled individuals at each age and figure 11 confirms that the common trend assumption is also satisfied for totally disabled individuals.

Figure 10. Predicted probability of joining the disability rolls before-after the reform:

Totally disabled individuals.

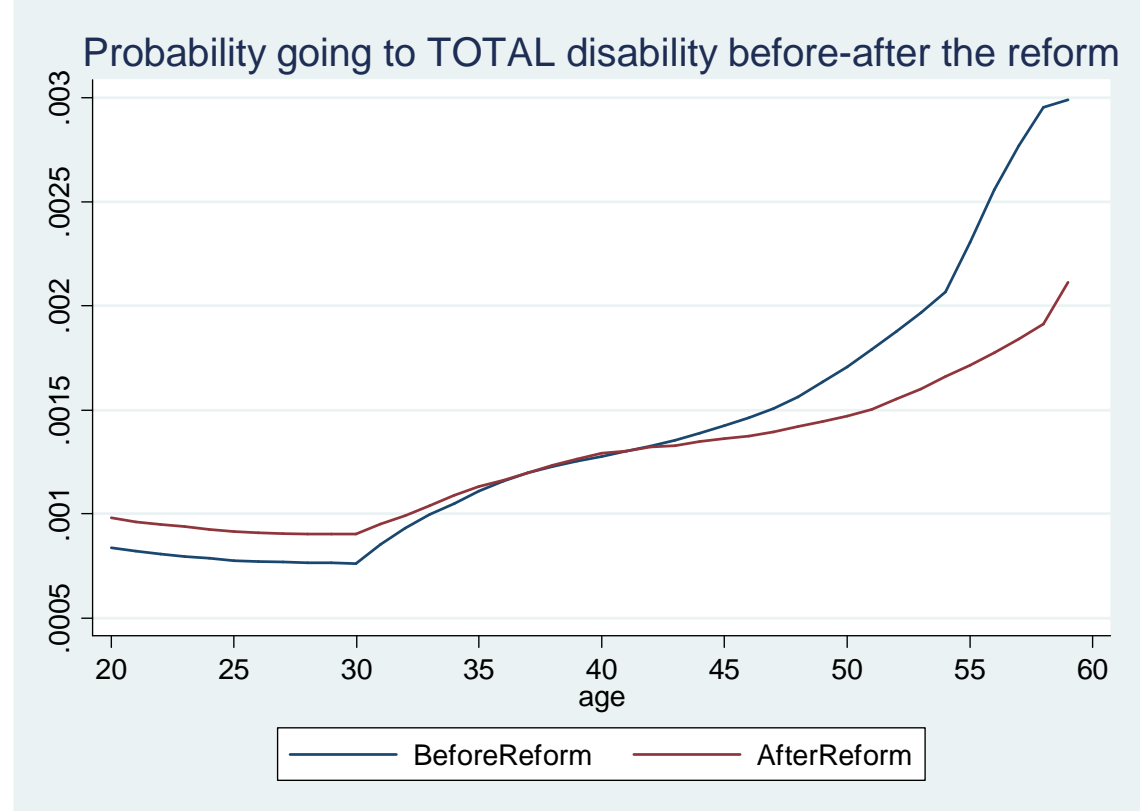


Figure 11. Predicted probability of entering the disability rolls: treated-control groups. Totally disabled individuals.

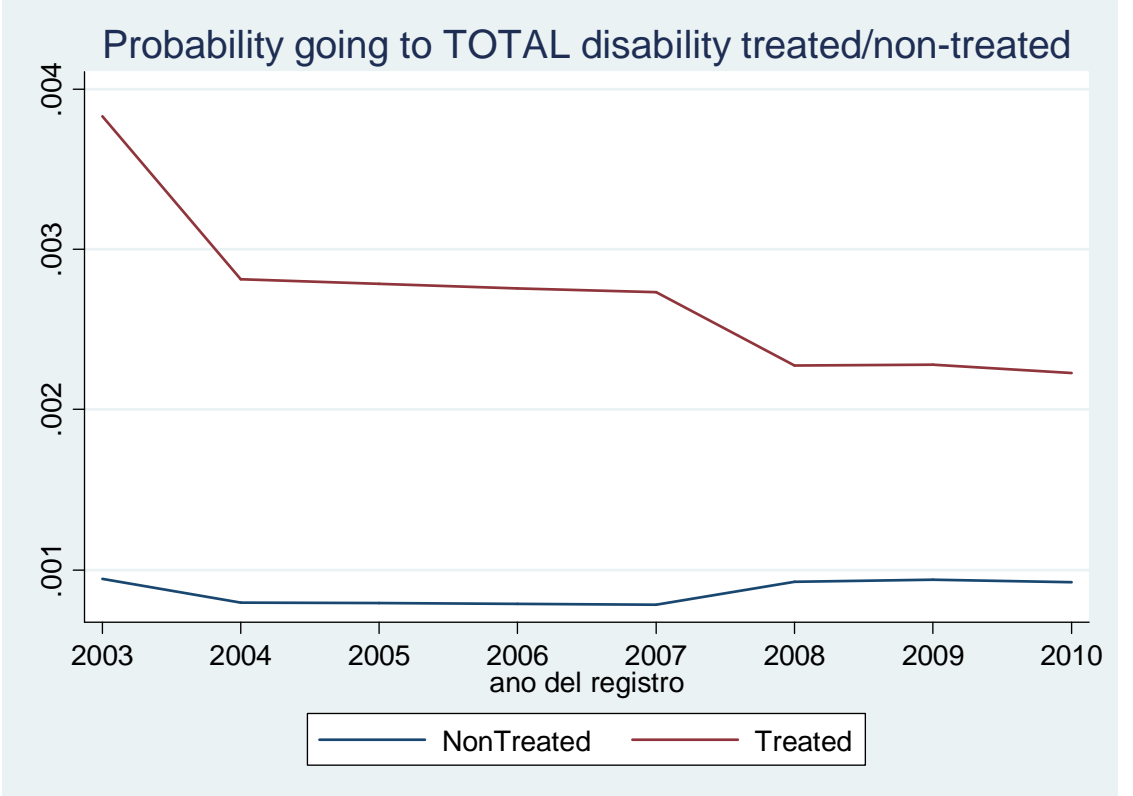




\section{CONCLUSIONS}

In Spain there are approximately one million of disabled individuals receiving disability benefits. Around half of them are still capable of developing a different job or professional activity to the one before becoming disabled. However, only twenty percent of these partially disabled individuals are working. In two recent studies, Marie and Vall (2012) and Silva and Vall (2012) study the incentives to work provided by the partial disability scheme in Spain and find the presence of strong disincentives to look for jobs for this group of workers.

In this paper we focus the analysis on the individual's incentives to apply to the Spanish disability system and we evaluate the extent to which these incentives are modified due to a policy change on the way to calculate the disability benefits introduced in 2008. To gain a theoretical insight we present a life-cycle model with heterogeneous disabled workers that compute the probability of becoming officially disabled and, therefore, receiving disability benefits. We show that this probability increases with age, especially after 33 years old. A special mention deserves its jump at 55 years old, coinciding with the increase of 20 per cent in the regulatory base. The jump in the probability of becoming disabled is due to the presence of a strong incentive to apply to the disability system.

In 2008, the Spanish government introduced a reform in the contributory disability system in order to make it more similar to the old-age system and to take into account the number of years that the individual has contributed to the system when calculating the level of disability benefits that he/she will receive. Before 2008, the regulatory base was calculated as an average of the last 8 years of work before becoming disabled. After 2008, there was a percentage applied to this regulatory base that depended on the number of years contributed to the Social Security system. These changes affected only one group of disability beneficiaries, the ones that have less than 35 years of effective contributions, while it left unchanged the formula to calculate the benefits for individuals with 35 or more years of effective contributions. We use this last group of individuals as a control group and apply a diff-diff strategy to estimate the disincentive to apply to the benefits as a result of this policy change. The results of the theoretical and empirical models are very similar and show that the reform decreases the probability of going to disability 
benefits for individuals aged 40 and onwards (who are the ones with less than 35 years of effective contributions). However, the estimations of the empirical model also show a slightly increase in the probability of joining the disability system for younger individuals.

Under the current context of a strong economic crisis that puts additional pressure for the government to cut expenditures and reduce the public deficit and debt, our results are important because they suggest that the reform in 2008 reduced the total number of individuals that enter the disability rolls each year. 


\section{APPENDIX}

Table1. Probability entering the disability rolls

\begin{tabular}{lcc}
\hline & Logit & Linear Probability \\
\hline \multirow{2}{*}{ Treatment } & $1.436^{* * *}$ & $0.00394 * * *$ \\
& $(0.0248)$ & $(8.58 \mathrm{e}-05)$ \\
After & $0.158^{* * *}$ & $0.000211^{* * *}$ \\
& $(0.0271)$ & $(3.64 \mathrm{e}-05)$ \\
Treatment*After & $-0.397 * * *$ & $-0.00131 * * *$ \\
& $(0.0377)$ & $(0.000124)$ \\
Constant & $-6.695^{* * *}$ & $0.00124 * * *$ \\
& $(0.0190)$ & $(2.34 \mathrm{e}-05)$ \\
Observations & $5,421,319$ & $5,421,319$ \\
\hline
\end{tabular}

Robust standard errors in parentheses

$$
* * * \mathrm{p}<0.01, * * \mathrm{p}<0.05, * \mathrm{p}<0.1
$$

Table 2. Probability entering the disability rolls

\begin{tabular}{lcc}
\hline & Logit & Linear Probability \\
\hline \multirow{2}{*}{ Treatment } & $1.465^{* * *}$ & $0.00394^{* * *}$ \\
& $(0.0252)$ & $(8.64 \mathrm{e}-05)$ \\
After & $0.204^{* * *}$ & $0.000305^{* * *}$ \\
& $(0.0429)$ & $(7.77 \mathrm{e}-05)$ \\
Treatment*After & $-0.388^{* * *}$ & $-0.00127 * * *$ \\
Self-employed & $(0.0379)$ & $(0.000124)$ \\
& $-0.316^{* * *}$ & $-0.000853^{* * *}$ \\
Female & $(0.0228)$ & $(5.14 \mathrm{e}-05)$ \\
& $-0.738^{* * *}$ & $-0.00140 * * *$ \\
Skill & $(0.0210)$ & $(3.97 \mathrm{e}-05)$ \\
& $-1.005^{* * *}$ & $-0.00171 * * *$ \\
GDP & $(0.0237)$ & $(3.77 \mathrm{e}-05)$ \\
& 0.00516 & $1.13 \mathrm{e}-05$ \\
Andalucia & $(0.00720)$ & $(1.47 \mathrm{e}-05)$ \\
Aragon & $0.642^{* * *}$ & $0.00125 * * *$ \\
& $(0.0364)$ & $(6.83 \mathrm{e}-05)$ \\
Asturias & 0.0699 & $7.02 \mathrm{e}-05$ \\
& $(0.0717)$ & $(0.000106)$ \\
Baleares & $0.622^{* * *}$ & $0.00116^{* * *}$ \\
Canarias & $(0.0620)$ & $(0.000153)$ \\
Cantabria & $0.134^{*}$ & 0.000137 \\
Castleon & $(0.0723)$ & $(0.000121)$ \\
& $0.115^{*}$ & $8.42 \mathrm{e}-05$ \\
& $(0.0588)$ & $(9.60 \mathrm{e}-05)$ \\
& $0.676^{* * *}$ & $0.00129 * * *$ \\
& $(0.0778)$ & $(0.000207)$ \\
& $0.319^{* * *}$ & $0.000464^{* * *}$ \\
& &
\end{tabular}




\begin{tabular}{lcc} 
& $(0.0511)$ & $(9.25 \mathrm{e}-05)$ \\
Castmancha & $0.458 * *$ & $0.000807 * * *$ \\
Catalunya & $(0.0527)$ & $(0.000116)$ \\
Valencia & $0.251 * * *$ & $0.000381 * * *$ \\
& $(0.0391)$ & $(5.88 \mathrm{e}-05)$ \\
Extremadura & $0.324 * * *$ & $0.000489 * * *$ \\
& $(0.0432)$ & $(7.30 \mathrm{e}-05)$ \\
Galicia & $0.576 * * *$ & $0.00107 * * *$ \\
& $(0.0620)$ & $(0.000154)$ \\
Murcia & $0.775^{* * *}$ & $0.00170^{* * *}$ \\
& $(0.0430)$ & $(0.000109)$ \\
Navarra & $0.470^{* * *}$ & $0.000824 * * *$ \\
& $(0.0583)$ & $(0.000130)$ \\
Paisbasco & $0.159^{*}$ & 0.000189 \\
& $(0.0941)$ & $(0.000152)$ \\
Rioja & $0.391 * * *$ & $0.000612 * * *$ \\
& $(0.0520)$ & $(9.20 \mathrm{e}-05)$ \\
Constant & $0.241 * *$ & 0.000351 \\
Observations & $(0.123)$ & $(0.000232)$ \\
& $-6.477 * * *$ & $0.00212 * * *$ \\
& $(0.0449)$ & $(7.72 \mathrm{e}-05)$ \\
& $5,408,911$ & $5,408,911$ \\
\hline
\end{tabular}

Robust standard errors in parentheses

$* * * \mathrm{p}<0.01,{ }^{* *} \mathrm{p}<0.05, * \mathrm{p}<0.1$

Table 3. Probability entering disability rolls: Total Disability

\begin{tabular}{lcc}
\hline & Logit & Linear Probability \\
\hline \multirow{2}{*}{ Treatment } & $1.272^{* * *}$ & $0.00204 * * *$ \\
& $(0.0322)$ & $(6.43 \mathrm{e}-05)$ \\
After & $0.179 * * *$ & $0.000156^{* * *}$ \\
& $(0.0336)$ & $(2.94 \mathrm{e}-05)$ \\
Treatment*After & $-0.374 * * *$ & $-0.000656 * *$ \\
& $(0.0485)$ & $(9.35 \mathrm{e}-05)$ \\
Constant & $-7.137 * * *$ & $0.000795 * * *$ \\
& $(0.0236)$ & $(1.88 \mathrm{e}-05)$ \\
Observations & $5,417,357$ & $5,417,357$ \\
\hline
\end{tabular}

Robust standard errors in parentheses

$* * * \mathrm{p}<0.01, * * \mathrm{p}<0.05, * \mathrm{p}<0.1$

Table 4. Probability entering disability rolls: Total Disability

\begin{tabular}{ccc}
\hline & Logit & Linear Probability \\
\hline Treatment & $1.352^{* * *}$ & $0.00211^{* * *}$
\end{tabular}




\begin{tabular}{|c|c|c|}
\hline & $(0.0330)$ & $(6.53 \mathrm{e}-05)$ \\
\hline \multirow[t]{2}{*}{ After } & $0.160 * * *$ & $0.000137 * *$ \\
\hline & $(0.0543)$ & $(6.03 e-05)$ \\
\hline \multirow[t]{2}{*}{ Treatment*After } & $-0.344 * * *$ & $-0.000621 * * *$ \\
\hline & $(0.0491)$ & $(9.25 e-05)$ \\
\hline \multirow[t]{2}{*}{ Self-employed } & $-0.329 * * *$ & $-0.000481 * * *$ \\
\hline & $(0.0310)$ & $(3.81 \mathrm{e}-05)$ \\
\hline \multirow[t]{2}{*}{ Female } & $-0.785 * * *$ & $-0.000929 * * *$ \\
\hline & $(0.0273)$ & $(3.11 \mathrm{e}-05)$ \\
\hline \multirow[t]{2}{*}{ Skill } & $-0.286 * * *$ & $-0.000308 * * *$ \\
\hline & $(0.0258)$ & $(3.10 \mathrm{e}-05)$ \\
\hline \multirow[t]{2}{*}{ GDP } & -0.00344 & $-4.04 \mathrm{e}-06$ \\
\hline & $(0.00911)$ & $(1.14 \mathrm{e}-05)$ \\
\hline \multirow[t]{2}{*}{ Andalucia } & $0.481 * * *$ & $0.000562 * * *$ \\
\hline & $(0.0461)$ & $(5.28 \mathrm{e}-05)$ \\
\hline \multirow[t]{2}{*}{ Aragon } & $0.171 * *$ & $0.000172 *$ \\
\hline & $(0.0860)$ & $(8.83 \mathrm{e}-05)$ \\
\hline \multirow[t]{2}{*}{ Asturias } & $0.886 * * *$ & $0.00131 * * *$ \\
\hline & $(0.0700)$ & $(0.000139)$ \\
\hline \multirow[t]{2}{*}{ Baleares } & -0.0847 & $-8.43 e-05$ \\
\hline & $(0.0999)$ & $(8.75 \mathrm{e}-05)$ \\
\hline \multirow[t]{2}{*}{ Canarias } & $-0.142 *$ & $-0.000149 * *$ \\
\hline & $(0.0816)$ & $(6.95 \mathrm{e}-05)$ \\
\hline \multirow[t]{2}{*}{ Cantabria } & $0.521 * * *$ & $0.000606 * * *$ \\
\hline & $(0.105)$ & $(0.000154)$ \\
\hline \multirow[t]{2}{*}{ Castleon } & 0.0110 & $-9.62 e-06$ \\
\hline & $(0.0708)$ & $(6.58 \mathrm{e}-05)$ \\
\hline \multirow[t]{2}{*}{ Castmancha } & $0.191 * * *$ & $0.000179 * *$ \\
\hline & $(0.0739)$ & $(8.13 \mathrm{e}-05)$ \\
\hline \multirow[t]{2}{*}{ Catalunya } & $0.556 * * *$ & $0.000674 * * *$ \\
\hline & $(0.0452)$ & $(5.23 e-05)$ \\
\hline \multirow[t]{2}{*}{ Valencia } & $0.306 * * *$ & $0.000321 * * *$ \\
\hline & $(0.0537)$ & $(5.83 e-05)$ \\
\hline \multirow[t]{2}{*}{ Extremadura } & $0.333 * * *$ & $0.000349 * * *$ \\
\hline & $(0.0870)$ & $(0.000108)$ \\
\hline \multirow[t]{2}{*}{ Galicia } & $0.231 * * *$ & $0.000219 * * *$ \\
\hline & $(0.0632)$ & $(7.01 \mathrm{e}-05)$ \\
\hline \multirow[t]{2}{*}{ Murcia } & $0.213 * * *$ & $0.000206^{* *}$ \\
\hline & $(0.0822)$ & $(9.18 \mathrm{e}-05)$ \\
\hline \multirow[t]{2}{*}{ Navarra } & $0.271 * *$ & $0.000271 * *$ \\
\hline & $(0.113)$ & $(0.000127)$ \\
\hline \multirow[t]{2}{*}{ Paisbasco } & $0.377 * * *$ & $0.000405 * * *$ \\
\hline & $(0.0639)$ & $(7.48 \mathrm{e}-05)$ \\
\hline \multirow[t]{2}{*}{ Rioja } & 0.0676 & $6.43 e-05$ \\
\hline & $(0.170)$ & $(0.000168)$ \\
\hline
\end{tabular}


Constant

$$
-7.033 * * *
$$

$0.00107 * * *$

(0.0554)

$(5.98 \mathrm{e}-05)$

Observations

$5,404,601$

$5,404,601$

Robust standard errors in parentheses

$* * * \mathrm{p}<0.01, * * \mathrm{p}<0.05, * \mathrm{p}<0.1$ 


\section{REFERENCES}

Autor, D. Duggan, M. 2003. The rise in the disability rolls and the decline in unemployment. Quarterly Journal of Economics; 118; 157-205.

Campolieti, M. Riddell, C. 2012. DisabilityPolicy and the labor market: Evidence from a natural experiment in Canada, 1998-2006. Journal of Public Economics; 96: 306-316.

Chen, S. Van der Klaauw, W. 2008. The Work Disincentive Effects of the Disability Insurance Program in the 1990s. Journal of Econometrics; 142; 757-784.

De Jong, P. Lindeboom, M. Van Der Klaauw, B. 2011. Screening Disability Insurance Applications. Journal of the European Economic Association; 9; 106-129.

Gruber, J. 2000. Disability Insurance Benefits and Labor Supply. Journal of Political Economy; 108: 1162-1183.

Gruber, J. Kubik, J.D. 1997. Disability Insurance Rejection Rates and the Labor Supply of Older Workers. Journal of Public Economics; 64; 1-23.

Jiménez-Martín, S. Vall-Castello, J. 2009. Business Cycle Effects on Labour Force Transitions for Older People in Spain. FEDEA Working Paper 2009-25.

Karlström, A. Palme, M. Svensson, I. 2008. The Employment Effect of Stricter Rules for Eligibility for DI: Evidence from a Natural Experiment in Sweden. Journal of Public Economics 92; 2071-2082.

Marie O. Vall Castello J. 2012. Measuring the (Income) Effect of Disability Insurance Generosity on Labour Market Participation. Journal of Public Economics 96; 198-210.

Silva, J.I. Vall Castello, J. 2012. Why are so many disabled individuals not working in Spain? A Job Search Approach. IZA discussion paper 6317.

Staubli, S. 2011. The Impact of Stricter Criteria for Disability Insurance on Labor Force 
Participation. Journal of Public Economics 95; 1223-1235. 